\title{
Intercultural Miscommunication in the Production of Communicative Patterns by Arab EFL Learners
}

\author{
Hameed Yahya A. Al-Zubeiry ${ }^{1}$ \\ ${ }^{1}$ Department of English, Faculty of Science and Arts, Baljurashi, AlBaha University, AlBaha, KSA \\ Correspondence: Dr. Hameed Y. Al-Zubeiry, Department of English, Faculty of Science \& Arts, Baljurashi, \\ AlBaha University, AlBaha, KSA. E-mail: hameedyahya@gmail.com
}

Received: July 1, 2013 Accepted: July 23, 2013 Online Published: September 23, 2013

doi:10.5539/ijel.v3n5p69 URL: http://dx.doi.org/10.5539/ijel.v3n5p69

\begin{abstract}
The present study is an attempt to describe how Arab learners of English produce culture-specific expressions that create potential miscommunication across cultures. Three related approaches - ethnography of communication, pragmatic failure and conversational Analysis - were reviewed so as to get insights into understanding such a phenomenon. The subjects of the study consist of 120 male Saudi and Yemeni learners of English. In order to elicit data for the study, the subjects were given a Multiple-choice Discourse Completion Test (MDCT) which consists of six situations wherein they picture themselves to be in the real situation and choose a response from the ones provided. The findings of the study showed that the hypothesized responses, which are Arab culture -specific communicative patterns, received high number of frequency compared to the other responses. Such communicative patterns are likely to cause miscommunication in situations like the ones described in the study. The study concluded that Arab speakers of English should be made aware of the misuse of such communicative patterns in order to minimize miscommunication in their communicative interaction across cultures.
\end{abstract}

Keywords: culture, communication, intercultural communication, miscommunication

\section{Introduction}

Communication and culture are two interrelated aspects of language learning. Culture is usually carried by the language, and language is used to communicate. According to Beamer and Varner (2008) "communications system such as language and non-verbal communication are products of culture. They are also tools intricately bound up in the processes of culture itself." Communication across cultures may fail without a good understanding of the different cultural communicative patterns between the non-native speaker of the target language and the native speaker. Based on his cultural experience, a non-native speaker of the target language often produces some communicative acts that could be misunderstood by the native speaker. For example, An Arab speaker of English may decline an offer to him to share food by saying "thank you" to the native speaker of English. This pattern of communication, however, is considered as an acceptance of the offer from the perspective of the culture of the native speaker of English. Such a cultural difference of Arab communicative patterns, therefore, is likely to lead to miscommunication between a native speaker and an Arab speaker of English

\subsection{Rationale of the Study}

There are often more problems in cross-cultural communication than in communication between people of the same cultural background. Each participant may interpret the other's speech according to his own cultural conventions and expectations. If the cultural conventions of the speakers are widely different, misinterpretations and misunderstandings can easily arise, even resulting in a total breakdown of communication. It has been observed that Arab speakers of English produce certain culture-specific spoken patterns that may lead to miscommunication in their communicative interaction in English. These communicative patterns can be interpreted with mutual understanding of the cultural conventions shared among interlocutors. This has been shown by a number of researchers in cross-cultural communication studies (Thomas, 1983, 1996; Chick, 1996; Shaules \& Abe, 1997; Xu Lisheng, 2004; Lingley, 2006).

Intercultural or cross-cultural communication is an interdisciplinary field of research that studies how people 
understand each other across group boundaries of various sorts: national, geographical, ethnic, occupational, class, or gender (Kramsch, 2001, p. 201). Ting-Toomey and Chung (2005, p. 3) define intercultural communication as "the symbolic exchange process whereby individuals from two (or more) different cultural communities negotiate shared meanings in an interactive situation." Intercultural communication creates awareness about the importance of understanding speech acts cross-culturally. The recognition of the meaning of a particular speech act in a given cultural setting is at the heart of successful intercultural communication (Lee, 2005; Al-Khateeb, 2009). According to Samovar and Porter (1982, p. 6) intercultural communication occurs whenever a message is produced by a member of one culture for consumption by a member of another culture, a message must be understood. Due to cultural variations in such situations of communication, the potential for misunderstanding and disagreement is highly expected. In order to address such a problem, it is crucial to highlight such potential intercultural miscommunications to the EFL learners.

\subsection{Purpose of the Study}

Considering that intercultural miscommunication is possible if native speakers of English and non - native speakers of English perceive the same expression differently, the present research intends to show how Arab speakers of English in the Arabian Peninsula produce culture-specific patterns that create potential miscommunication with native speakers of English. Having insights into dynamics of a culture can be very helpful to understand why people act the way they do, and the appropriate way one should act while in that culture.

\subsection{Hypotheses of the Study}

The study has the following Hypotheses:

1-Arab learners of English tend to produce certain culture - specific patterns in their communication in English;

2-These communicative patterns are likely to create miscommunications across cultures.

\subsection{Limitation of the Study}

The present study is limited to six communicative patterns that are frequently observed in use among Arab learners of English. These patterns are as follows:

1-Any service to you: taking leave

2-Thank you: declining someone's invitation in sharing meal

3-Yes: responding to someone's negative - structured question

4-Ok: giving an indirect refusal to a friend's request

5-Ok, you have your own excuse: accepting someone's excuse

6-Insha Allah: assuring one's acceptance of doing something

\subsection{Intercultural Communication vs. Cross-Cultural Communication}

Intercultural communication and cross-cultural communication are two well-known terms that are associated with the study of variations in cultural communication across languages. Chick (2006) distinguishes between these two terms. He reserves the term 'cross-cultural' for studies exploring particular features of communication (e.g., compliments, refusals, apologies, turn-taking) across two or more cultures. He uses the term 'intercultural communication' to refer to studies that, by contrast, focus on particular intercultural encounters, and attend to whatever communication features are salient in them. As the present study focuses on the potential miscommunication that may arise because of the different cultural communicative patterns encountered by native speakers of English, the researcher prefers to use the term intercultural communication over cross-cultural communication. It seems worthy to indicate, however, that these two terms have been used interchangeably in the literature.

\section{Literature Review}

Among the important approaches that look into the study of diverse intercultural communication patterns are ethnography of communication, pragmatic failure and conversational Analysis. These approaches give insights into understanding how certain culture-specific communication patterns are likely to be misunderstood between interlocutors of native speakers and non-native speakers of language.

\subsection{Ethnography of Communication}

Ethnography of communication, introduced in the 1960s by Hymes \& Gumoerz (1964), is primarily concerned with the analysis of language use in its cultural setting. Keating (2001, p. 286) indicates that "the project 
(ethnography of communication) was initiated and named with the publication of a 1962 paper by Hymes called 'The Ethnography of Speaking', in which Hymes proposed combining ethnography, the description and analysis of culture with linguistics, the description and analysis of language." Traditionally, linguists studied the structure and function of language and attempted to understand how the people of a given society typically communicate with each other. Recently, anthropologists have begun to investigate how people in a society vary in how they speak.

As an approach of sociolinguistic studies, the ethnography of communication aims at describing the forms and functions of verbal and non-verbal communicative behaviour in a particular social setting (Keating, 2001). According to Carbaugh (2008), the approach is concerned with:

1-the linguistic resources people use in context, not just grammar in the traditional sense, but the socially situated uses and meanings of words, their relations, and sequential forms of expression;

2-the various media used when communicating, and their comparative analysis, such as online "messaging" and how it compares to face-to-face messaging;

3-the way verbal and non-verbal signs create and reveal social codes of identity, relationships, emotions, place, and communication itself.

Considering the significance of the ethnography of communication approach for the field of applied linguistics, Saville-Troike, (2003, p. 7) maintains "...one of the most significant contributions made by the ethnography of communication is the identification of what a second language learner must know in order to communicate appropriately in various contexts in that language, and what the sanctions may be for any violations or omissions. There are also important applications for contrasting whole communicative systems in cross-cultural interaction and translation, and for recognizing and analyzing communicative misunderstandings."

In view of the main goal of the present study, the ethnography of communication approach provides insights into understanding how the Arab speakers of English produce certain culture-specific communicative patterns that are likely to be misunderstood across cultures.

\subsection{Pragmatic Failure}

Pragmatic failure refers to the speaker's production of wrong communicative effects through the faulty use of speech acts or one of the rules of speaking (Richards, Platt, \& Platt, 1992, p. 127). The speech act is used by Crystal $(1992$, p. 362) to refer to a communicative activity defined with reference to the intentions of a speaker while speaking and the effects achieved on a listener. Non - native speakers of the target language sometimes fail to communicate effectively across culture. They may produce speech acts that do not conform to the culturally-bound speech acts of the native speaker's language.

Thomas (1983) defines pragmatic failure as "...the inability to understand what is meant by what is said." She also indicates that cross cultural pragmatic failure can occur on any occasion "On which $\mathrm{H}$ (the hearer) perceives the force of S's (the speaker's) utterance as other than S intended she or he should perceive it" (Thomas, 1983, p. 91).

Thomas (1983, p. 97) classified pragmatic failure into two groups: pragmalinguistic failure and sociopragmatic failure. In her study, Thomas states, "Pragmalinguistic failure occurs when the pragmatic force mapped by students onto a given utterance is systematically different from the force most frequently assigned to it by native speakers of the target language, or when conventional strategies are inappropriately transferred from the speaker's mother tongue to the target language". Sociopragmatic failure arises when learners produce socially inappropriate behavior. Different culture has different assessment towards "size of imposition", "relative rights and obligations", thus affecting linguistic choice

In another relevant classification of pragmatic failure, He Ziran, \& Chen Xinren (2004) maintain that pragmatic failure can be viewed from a three-fold perspective namely, pragmalinguistic failure, sociopragmatic failure and pragmatic failure in cross-cultural communication. Pragmalinguistic failure is realized in consideration of the participants (i.e., the speaker and the listener) involved in the conversation. It happens that the speaker commits pragmatic failure when he thinks that the listener can realize what he means and accordingly he uses an unsuitable expression for communication. Similarly, the listener commits pragmatic failure when he misunderstands the speaker's expression. Sociopragmatic failure occurs when the speaker does not pay attention to the identity and social status of the listener during the conversation. He may commit pragmatic failure when he produces an expression or addresses someone of a higher social status with an intimate form. Such an occurrence of sociopragmatic failure could be attributed to the speaker's lack of knowledge about the politeness principle of social interaction. Pragmatic failure in cross-cultural communication occurs due to the following 
summarized reasons:

1. The speaker's choice of an inappropriate topic that has different value views across cultures.

2. The speaker's use of expressions that have different implications in the target language or deviate from his own intention in producing such an expression.

3. The speaker's misuse of an utterance expressing a certain idea but does not conform to the convention of the target language.

4. A participant's inappropriate response to a certain question or statement.

Keeping in mind the main purpose of the present study, pragmatic failure approach lends itself into understating how an utterance made by the non-native speaker of the target language in expressing a certain idea may fail. This probably results in miscommunication with the native speaker. The miscommunication (failure) could be attributed to the reason that such an utterance may not conform to the convention of the native speaker's language.

\subsection{Conversational Analysis}

Conversational Analysis was developed by Sacks and his associates, Schegloff and Jefferson, in the late 1960s and the early 1970s. It aims at the analysis of the methods people use to engage in conversation and other forms of social interaction involving speech. Its central concern is to determine how individuals experience, make sense of, and report their actions.

Considering how communication is likely to be organized between interlocutors, 'adjacency pairs' is viewed as the basic structural unit of conversational analysis studies of spoken language. Adjacency pairs refer to 'conversational sequences' in which an utterance by one speaker depends upon an utterance made by another speaker. It is a sequence of two related utterances by two different speakers. The second utterance is always the response to the first. It is known as 'a tied pair' (Coulthard, 1985). Examples of adjacency pairs are commonly realized in pair-tied sequences like: 'greeting-greeting, 'question-answer', summons-response', and 'blame-denial'.

Cook (1989, pp. 53-54) points out that in an adjacency pair, there is often a choice of two likely responses. A request is likely to be followed by either acceptance or a refusal. In such cases, one of the responses is termed 'preferred' response (because it occurs most frequently) and the other the 'dispreferred' response (because it is less common).

In view of the purpose of the present study, conversational analysis (Adjacency pair sequences) provides insights into understanding how a sequence of two related utterances by two different speakers are organized. Any problem of such organization is likely to lead to miscommunication between interlocutors.

Problems of culture-specific communicative patterns of Arab EFL learners have not been widely investigated in the literature of cross-cultural communication. However, there are few studies which may provide insights into understanding such problems. For instance, Zheng and Huang (2010) conducted a study of Chinese EFL learners' pragmatic failure and their implications for college English teaching. The purpose of the study was to investigate the pragmatic failures that college English learners tend to commit in cross-cultural communication through questionnaires and interviews. The results of the study showed that cultural differences between China and English-speaking countries are considered as barriers to communication across cultures. Differences in social conventions, value views, thinking patterns, social habits and customs are all sources of pragmatic failure which inevitably lead to misunderstanding.

In the context of Arab world, Shammas (1995) carried out a thesis entitled "cross cultural pragmatic failure: misunderstanding in verbal communication between speakers of Arabic and English". The thesis discussed the most frequent cases of misunderstanding in verbal communication between speakers of Arabic and English. The findings of the thesis showed that linguistic well-formedness is important in cross-cultural communication, but cultural codes and socio-cognitive principles impede the addressee's understanding of the speaker's intent far more. The study also indicated that the degree of communicative breakdown caused by cultural mismatch is much higher than that of linguistic errors. Cultural discrepancy also provides great potential for misunderstanding in extended contexts of cross-cultural communication. It should be made clear that due to the reason of inaccessibility of this work, it was difficult to review how the study is conducted.

Considering the above mentioned studies, we may observe that both the studies considered cultural discrepancy, social conventions and thinking patterns as the potential sources of pragmatic failure which inevitably lead to miscommunication. The present study attempts to describe how Arab EFL learners produce culture-specific 
communicative patterns which are likely to create miscommunication across cultures.

\section{Methodology}

\subsection{Subjects}

As the main purpose of the study is to show how Arab learners of English produce certain culture-specific communicative patterns that create potential miscommunication with native speakers of English, a number of 120 male Saudi and Yemeni university learners was selected as subjects for the present study. These subjects are enrolled in the departments of English in the following universities:

- Faculty of Languages \& Translation - King Khalid University- Abha, KSA.

- Faculty of Science and Arts- Baljurashi, AlBaha University- AlBaha, KSA.

- Faculty of Education - Sana'a University, Yemen.

- Faculty of Education, Al-Mahweet - Sana'a University, Yemen

Thirty subjects from each faculty were taken randomly as representatives of Arab learners of English (i.e., the Arabian peninsula part). It is worth mentioning that the subjects had had two English courses of speaking and listening prior to their participation in the study. In these two courses they were exposed to different situations of communication in English.

\subsection{Instrument and Procedures}

The instrument used for the purpose of the present study is a Multiple - choice Discourse Completion Test (MDCT, i.e., a tool used for collecting data through responding to real-like situations). The MDCT consists of six items in which the subject is expected to choose a response from the options provided. Each item is composed of a short description of the situation, specifying the setting, the social distance between the participants and their status relative to each other.

The development of the test is made in consideration of some prior steps. Firstly, a pilot Written Discourse Completing Test (WDCT) was administered to 30 Arab learners of English. They were asked to write their responses to certain situations where the potential patterns of miscommunication is to occur. It is assumed that such a WDCT can inform us of how respondents' pragmatic knowledge is activated (Martinez-Flor, 2006). Secondly, the data and feedback collected from the pilot WDCT was considered in forming the MDCT and weeding out any possible misunderstandings or vague parts in the scenarios. The responses given in the previous step were used as the alternative options along with the hypothesized responses. Moreover, It is necessary to point out that an empty slot option was provided to the subjects to respond to the situations if the other provided options do not conform to their choices. Thirdly, the developed MDCT was given to two Arab experts in the field of study for validation. Their suggestions and observations were taken into consideration in designing the final version of the MDCT. For further validation the MDCT was discussed with an American native speaker of English who suggested some amendments to the test. It is worthy to mention that the steps followed in developing the MDCT match the ones applied by Birjandi \& Rezaei, (2010) in assessing the pragmatic knowledge of Iranian EFL learners in relation to the speech acts of request and apology in EFL classrooms.

After making sure of the validity of the instrument of the study, the (MDCT) version was administered to the target subjects. The allotted time for conducting the test was 20 minutes only for the purpose of eliciting spontaneous responses. Instructions on the test were given clearly. Each situation was read out separately and the subjects were asked to respond to each one respectively.

\section{Data Analysis: Results and Discussion}

This section presents the results of the study. It attempts to answer the study hypotheses which read: Arab learners of English tend to produce certain culture - specific patterns in their communication in English; These communicative patterns are likely to create miscommunications across cultures. The results were collected and tabulated in terms of frequency and percentage. They are as follows:

\subsection{Situation 1: Any Service to You - Taking Leave}

"You come across one of your classmates on campus. He greets you and inquires about something you had in class. You answer him and he thanks you. You want to leave." You would say: 
Table 1. Frequency and percentage of subjects' responses to situation 1

\begin{tabular}{lll}
\hline Response & Frequency & Percentage \% \\
\hline See you soon & 29 & 24.17 \\
Any service to you & 62 & 51.67 \\
I have to go now & 18 & 15.00 \\
Other... & 11 & 9.17 \\
\hline
\end{tabular}

Table 1 shows the results of how Arab learners respond to situation of leave-taking. It can be observed that the hypothesized communicative pattern (i.e., any service to you) receives the highest frequency of responses namely, $62(51.67 \%)$. 'See you soon' response comes next with 29 (24.17\%). The "I have to go now" response forms 18 $(15 \%)$; and the 'other' response is $11(15 \%)$.

In taking leave after having conversation, Arabs are usually used to saying 'ay Khedmah lek' (literally means 'any service to you'). Such a communicative pattern, however, may function as an offer of help from the perspective of native speakers of English. The production of the communicative pattern, 'any service to you', in such a situation is likely to bring about miscommunication between interlocutors across cultures.

\subsection{Situation 2: Thank you - declining someone's invitation in sharing food}

"It happens that you sit at the same table where a native English friend of yours is having his food. He invites you to share food with him. He says 'please share with me'." Declining, you say:

Table 2. Frequency and percentage of subjects' responses to situation 2

\begin{tabular}{lll}
\hline Response & Frequency & Percentage \% \\
\hline Thank you & 54 & 45.00 \\
No thank you & 44 & 36.67 \\
Oh, I'm full. & 17 & 14.17 \\
Other... & 5 & 4.17 \\
\hline
\end{tabular}

Considering the results of the learners' responses to the situation of declining an invitation of sharing food in table 2, we observe that the hypothesized communicative pattern, i.e., 'Thank you', is the highest among the other responses with $54(45.00 \%)$. 'No thank you' response comes in the next place with $44(36.67 \%)$ and it is followed by 'Oh, I'm full' response which receives 17 (14.17). The 'other' response is 5 (4.17\%).

An invitation is usually followed by two adjacency pairs: acceptance (preferred response) or declining (disprefered response). Based on the conventions of the native speakers of English, the response 'Thank you' acts as an acceptance of invitation. This pattern of response, however, does not act as an acceptance of invitation from the perspective of the Arab cultural norms. In fact, it acts as a polite rejection of the invitation. Such a communicative pattern could lead to miscommunication between native speakers of English and Arab learners of English in the course of interaction.

\subsection{Situation 3: Yes-Responding to Someone's Negative Structured Question}

"A group of your classmates are planning to go for a picnic next week. You are not interested in going with them. A native English friend of yours approaches you asking: Aren't you coming along with us?" You would say:

Table 3. Frequency and percentage of subjects' responses to situation 3

\begin{tabular}{lll}
\hline Response & Frequency & Percentage \% \\
\hline Thank you. & 20 & 16.67 \\
No & 51 & 42.50 \\
Yes & 42 & 35.00 \\
Other... & 7 & 5.83 \\
\hline
\end{tabular}


The above table reveals that the response ' $N o$ ' receives the highest number of frequency with $51(42.50 \%)$. The hypothesized response 'Yes' comes next with $42(35.00 \%)$. The other responses vary from $20(16.67 \%)$ in the response of 'Thank you' to 7 (5.83\%) in the response of 'Other'.

Though the frequency of "No" response is higher than that of the hypothesized one (i.e., 'Yes'), the minor difference between the two shows the tendency towards the use of 'Yes' instead of ' $N o$ ' when answering a negative-structured question. Unlike English people, Arabs tend to answer a negative-structured question with 'Yes' in their communication; it implies a dispreferred answer from the perspective of the speaker. Such a pattern of spoken response, therefore, is likely to cause miscommunication between Arab EFL learners and native speakers of English.

\subsection{Situation 4: Ok-Giving an Indirect Refusal to a Friend's Request}

"One of your friends requests you to lend him your class notebook tomorrow. You try to apologize, but he insists asking for it. You want to indirectly refuse his request. Your friend says: 'please give it to me'." You say:

Table 4. Frequency and percentage of subjects' responses to situation 4

\begin{tabular}{lll}
\hline Response & Frequency & Percentage \% \\
\hline Let me see. & 46 & 38.33 \\
Ok & 37 & 30.83 \\
Of course & 30 & 25.00 \\
Other... & 7 & 5.83 \\
\hline
\end{tabular}

Table 4 indicates that the response, 'Let me see', constitutes the highest number of frequency with 46 (38.33\%). The hypothesized response 'Ok' comes next with 37 (30. 83). 'Of course' and 'Other' responses receive 30 $(25.00 \%)$ and 7 (5.83\%) respectively.

In spite of the fact that the results above indicate that the percentage of the response 'Let me see' receives the highest number of frequency compared to the hypothesized one (i.e., Ok), the hypothesized response still shows significance as it comes next in order. In fact, Arabs often tend to avoid direct rejection of a friend's request. They usually use the utterance ' $O k$ ' to evade giving a positive preferred response to his request. However, such a response could be considered as a preferred answer from the perspective of the native speakers' norms of communication as such it may create miscommunication across cultures.

\subsection{Situation 5: Ok, You Have Your Own Excuse-Accepting Someone's Excuse}

"You are in the class. Your native English teacher tells that he won't be able to come for the next class on the grounds that he has a meeting somewhere. You respond to his notice." You would say:

Table 5. Frequency and percentage of subjects' responses to situation 5

\begin{tabular}{lll}
\hline Response & Frequency & Percentage \% \\
\hline Ok sir & 40 & 33.33 \\
Ok, you have your own excuse & 50 & 41.67 \\
It's ok & 29 & 24.17 \\
Other... & 1 & 0.83 \\
\hline
\end{tabular}

A cursory look at table 5 indicates that the hypothesized response, 'Ok, you have your own excuse', is the highest among the other responses with $50(41.67 \%)$. 'Ok sir' response comes in the second place with $40(33.33 \%)$. 'It's $o k$ ' response receives 29 (24.17) and 'Other' response is 1 (083).

Miscommunication across cultures sometimes brings about a serious consequence to the participants. The response 'ok, you have your own excuse', to the native English teacher's spoken notice in the situation described above could be misunderstood as an offensive indication of misbehaviour from the student. Arab people sometimes show intimacy towards their interlocutors when they give excuses for not being able to fulfil a task. They usually say 'odhrak ma'ak' (literally means 'you have your own excuse). 


\subsection{Situation 6: Insha Allah - Assuring One's Acceptance of Doing Something}

"You are in the class of English grammar. Your native English teacher instructs you to do an exercise on the book and bring it in the next class. Teacher says: 'do the exercise on page 72 and bring it in the next class'." You would say:

Table 6. Frequency and percentage of subjects' responses to situation 6

\begin{tabular}{lll}
\hline Response & Frequency & Percentage \% \\
\hline Insha'Allah & 83 & 69.17 \\
Ok sir & 22 & 18.33 \\
All right & 12 & 10.00 \\
Other... & 3 & 2.50 \\
\hline
\end{tabular}

Table 6 interestingly shows that the hypothesized response 'Insha'Allah' receives the highest number of frequency compared to the other responses, i.e., $83(69.17 \%)$. ' $O k$ sir' response comes next with 22 (18.33). The responses 'all right' and 'Other' constitute 12 (10.00\%) and 3 (2.50\%) respectively.

According to Kharrat (2002), "The phrase, "Insha'allah" (God willing), abundantly permeates Arabic conversation. A native English teacher might be confused by the student's intention when using such a statement, because, in English, it carries the connotation of 'maybe' or 'some day'. Accordingly, when an Arabic EFL student is instructed to write an assignment, and says 'insha' alla' to his teacher in response to the instruction, the latter might be exasperated because he expects his instructions to be followed as a matter of discipline, not as a matter of 'insha'allah' (I will do that, if God wills)".

\section{Conclusion}

The study aimed at describing how Arab EFL learners produce Arab culture-specific communicative patterns that probably create potential miscommunication with native speakers of English. The findings of the study showed that these communicative patterns received comparatively high frequency of responses in the hypothesized situations. Such high frequency of responses could be an indicator of potential miscommunication across cultures. In accordance with the analysis of the targeted types of communicative patterns that occur in intercultural interaction based on the data of the MDCT, cultural difference, religious rooted - norms, social conventions and pragmatic transfer are considered as being the four major sources of pragmatic failures which may cause breakdown of communication across cultures. The study concluded that Arab EFL learners should be made aware that communication is not confined to linguistic competence; in fact, they should have knowledge about pragmatic competence for communication. This could be achieved through involving them in culturally oriented English communication practice to minimize miscommunication in their communicative interactions across cultures. Role - play and discourse completion tasks are good examples of language communication practice that may improve the Arab EFL learners' communicative competence and get them aware of culture-specific patterns of communications.

\section{References}

Al-Khateeb, S. (2009). The Speech Act of Thanking as a Compliment Response as used by the Arab Speakers of English a Comparative Intercultural Study. Unpublished MA Thesis, An Najah National University, Nablus, Palestine.

Beamer, L., \& Varner, I. (2008). Intercultural Communication in the global workplace. New York: McGraw-Hill Irwin.

Birjandi, P., \& Rezaei, S. (2010). Developing a multiple-choice discourse completion test of interlanguage pragmatics for Iranian EFL learners. ILI Language Teaching Journal (Special Issue: Proceedings of the First Conference on ELT in the Islamic World), 6(1-2), 43-58.

Boxer, D. (2004). Studying Speaking to Inform Second Language Learning: A Conceptual Overview. In D. Boxer, \& A. Cohen (Eds.), Studying Speaking to Inform Second Language Learning. Clevedon: Multilingual Matters.

Carbaugh, D. (2008). Ethnography of communication. In W. Donsbach (Ed.), The International Encyclopedia of Communication. Vol. 4 (pp. 1592-1598). Oxford, UK and Malden, MA: Wiley-Blackwell. 
Chick, J. K. (1996). Intercultural Communication. In S. L. McKay, \& N. H. Hornberger (Eds.), Sociolinguistics and Language Teaching (pp. 329-348). Cambridge: Cambridge University Press.

Cook, G. (1989). Discourse. Oxford: Oxford University Press.

Coulthard, M. (1985). An Introduction to Discourse Analysis. London: Longman.

He, Z.-R., \& Chen, X.-R. (2004). Contemporary Pragmatics. Beijing: Foreign Language Teaching and Research Press.

Hymes, D. (1962). The Ethnography of Speaking. In T. Gladwin, \& W. C. Sturdevant (Eds.), Anthropology and Human Behavior (pp. 15-53). Washington, DC: Anthropological Society of Washington.

Hymes, D. (1964). Introduction: Toward ethnographies of communication. In J. Gumperz, \& D. Hymes (Eds.), The Ethnography of Communication. American Anthropologist, 66(6), part II.

Keating, E. (2001). The Ethnography of Communication. In P. Atkinson, A. Coffey, S. Delamont, L. Lofland, \& J. Lofland (Eds.), Handbook of Ethnography (pp. 283-301). London: Sage. http://dx.doi.org/10.4135/9781848608337.n20

Kharrat, Y. (2002). Learning the Culture as well as the Words. Humanising Language Teaching, 4(1). Retrieved from http://www.hltmag.co.uk/jan02/sart2.htm

Kramsch, C. (2001). Intercultural communication. In R. Carter, \& D. Nunan (Eds.), The Cambridge Guide to Teaching English to Speakers of Other Languages (pp. 201-206). Cambridge University Press. http://dx.doi.org/10.1017/CBO9780511667206.030

Lee, C. (2005). A cross-linguistic study on the linguistic expressions of Cantonese and English requests. Pragmatics, 15(4), 395-422.

Lingley, D. (2006). Apologies Across Cultures: An Analysis of Intercultural Communication Problems Raised in the Ehime Maru Incident. Asian EFL Journal, 8, 97-122.

Martínez-Flor, A. (2006). Task effects on EFL learners' production of suggestions: A focus on elicited phone messages and Emails. Journal of English and American Studies, 33, 47-64. Retrieved from $\mathrm{http} / / / \mathrm{www}$. theasa.net/journals/name/miscelanea a_journal_of_english_and_american_studies/

Samovar, L. S., \& Porter, R. E. (1982). Intercultural Communication: A Reader. Belmont (CA): Wadsworth.

Saville-Troike, M. (2003). The Ethnography of Communication: An Introduction. USA, UK, Australia, Germany: Blackwell Publishing Ltd. http://dx.doi.org/10.1002/9780470758373

Shammas, N. (1995). Cross-cultural pragmatic failure: Misunderstanding in verbal communication between speakers of Arabic and English. Unpublished Ph. D Thesis, Loughborough University Leicestershire, UK. Retrieved from https://dspace.lboro.ac.uk/dspace-jspui/handle/2134/7326

Shaules, J., \& Abe, J. (1997). Different Realities adventures in Intercultural Communication. Tokyo: Nan'undo.

Thomas, J. (1983). Cross-cultural Pragmatic Failure. Applied Linguistics, 4, 19-112. http://dx.doi.org/10.1093/applin/4.2.91

Ting-Toomey, S., \& Chung, L. C. (2005). Understanding intercultural communication. New York: Oxford University Press.

Yule, G. (1996). Pragmatics. Oxford: Oxford University Press.

Zheng, L., \& Huang, J. (2010). A Study of Chinese EFL Learners' Pragmatic Failure and the Implications for College English Teaching. Polyglossia, 18, 41-54.

\section{Copyrights}

Copyright for this article is retained by the author(s), with first publication rights granted to the journal.

This is an open-access article distributed under the terms and conditions of the Creative Commons Attribution license (http://creativecommons.org/licenses/by/3.0/). 